\title{
Cultural and Creative Industry and the Fourth Wave Economy: Analysis the Communication and Culture of Taiwan Film
}

\author{
Chao-Qun Shen ${ }^{1, a}$ \\ ${ }^{1}$ Department of Internet and New Media, Sanda University, Shanghai, China \\ a184532585@163.com
}

\begin{abstract}
"Cultural Creative Industry" is a global trend industry, which is what the Frankfurt School calls "cultural industry". film industry with communication technology development and global media influence, have high output value and high investment-benefit ratio. Through Taiwan films in global tickets, analyze the cultural communication and film industrialization.
\end{abstract}

Keywords: Cultural and creative industry, cultural industry, film, communication, cultural symbols

\section{文创产业与第四波经济：台湾电影文化传播分析 \\ 沈超群 1 , a}

\author{
1 上海杉达学院网络与新媒体系, 上海, 中国 \\ aghinishen@gmail.com
}

\section{摘要}

「文化创意产业」是全球各国极力推动的产业，是法兰克福学派所说之「文化工业」。随着传播方式的进展、 全球化的趋势影响，电影做为文创产业的一环，更是拥有高产值及高投资效益比的产业，透过台湾电影在全球 票片的分析，探讨电影与文化传播在文创产业的意涵。

关键词：文创产业，文化工业，电影，传播,文化符号

\section{1.前言}

随着「文化创意产业」受到全球重视，「文化工业」 的发展也成为两岸三地的重要产业, 由于电影是文化 产业重要的产值输出, 根据统计公司 Comscore 数据 显示, 2019 年全世界电影总票房收入为 425 亿美元, 创下历史新高, 这还不包含相关从业人员及外围厂商 的产值, 可见文创产业的发展已成为国际重点发展产 业。如今重塑 1980-1990 年代主流阅听人成长故事的 青春电影, 做为文化工业的商品, 营造票房的成功性, 包括台湾的《那些年, 我们一起追的女孩》、《我的少 女时代》; 大陆的《你好, 李焕英》、《夏洛特烦恼》 等, 都是类似性的作品。本文从「文创产业」的角度, 分析文化工业的产业价值。

\section{2. 文化工业概念}

「文化工业」是由德国法兰克福学派所提出的构 想, 法兰克福学派形成于 1930 年代, 在 1938 年学者 阿多诺（Theodor W. Adorno）撰写〈关于音乐中的拜 物教性质及听觉的倒退〉等论文, 开始全面探讨大众 文化; 阿多诺和班雅明（Walter Benjamin）就文化中 大众化、技术化、商品化的社会功能展开争论。在 1944 年，霍克海默（Max Horkheimer）在〈艺术与大众文 化〉文中，首次把大众文化与文化工业联系在一起， 认为文化工业就是「文化操纵」。因此文化工业乃是 由主流的操作而成型，如同其他工业产业，是具有相 同的可复制性、模块化与泰勒化（Taylorization）等特 征。 


\section{1. 文化工业与大众传播}

法兰克福学派最初使用「大众文化」, 后来则用 「文化工业」, 因为大众文化与文化工业有极强连结 性, 从法兰克福学派的观点来看, 文化工业即「现代 大众文化」, 除了具有一般意义上大众文化的内涵, 根据学者陈学明 (1996) 在《文化工业》中分析具有 以下特点: 文化的产生越来越类似于现代工业的生产 过程; 文化的产生与现代科学技术的结合越来越紧密; 文化的主体越来越不是作为文化消费者的广大人民 群众。

现代大众文化有专营的制作人、经营者，这些人 对大众文化起着主宰作用。在大众文化的市场利益份 额中, 他们是主要得利者。

社会学家贝尔 (Daniel Bell) 在《资本主义的文 化矛盾》中指出: 从社会学家角度分析, 文化大众有 三种类型的构成者。它包括的不懂有文化的创作者, 还有它的传播者..., 正是同一群人, 作为作家、杂志 编辑、电影制片人和音乐家等等, 为更多的大众文化 观众生产普及的产品。而在这三种类的人中, 创作者、 传播者主宰着大众文化的方向和面貌, 是文化大众的 中坚, 是他们塑造着广大观众、读者的审美趣味。

阿多诺讨论了文化工业体系的内在逻辑以及各 种动力的运作, 阿多诺认为在文化工业体系中, 每个 人同时具备生产者与消费者的身份, 不仅在物质上生 产并消费生产的东西, 同时也在概念上重复这样的循 环。学者陈畑志 (2005) 在文章〈逄车: 规范、快感 与文化工业的三螺旋〉认为, 「正因为电影总是想去 制造常规观念的世界, 所以, 常看电影的人也会把外 部世界当成他刚刚看过的影片的延伸, 这些人的过去 经验变成了制片人的准则。他复制经验客体的技术越 严谨无误, 人们现在就越容易产生错觉, 以为外部世 界就是屏幕上所呈现的世界那样, 是直接和延续的。」

文化工业或文化创意产业是现今历史经世致用 的主流之一, 时至今日, 文化产业仍然以电影、电视 为主要内容, 所占比重超过百分之五, 仔细分析起来, 电影是典型的文化产业, 它的源头是戏剧这种精致文 化, 也就是表演艺术。学者汉宝德 (2014) 认为, 在 各种艺术形式中, 表演艺术是由宗教娱神活动中演化 出来的, 本来就有一些群众性, 当它成为一种高级的 生活艺术时, 也很少发生拥有者独享的情形。这样的 方式也让文化「产业化」, 得以传播出更多型态。

从文化产业角度, 均可说明电影的塑造对于文化 的影响, 电影的虚构性无庸置疑, 但是当电影呈现过 去的内容时, 架构在集体记忆中的虚构, 却容易幻化 成为阅听人记忆的一环, 这也是现代电影卖座的潮流 之一。当 1980-1990 年代已成为阅听受众主流, 塑造 集体记忆的怀旧电影, 已成为成功的文化工业商品, 像是 2021 年迄今票房榜首《你好, 李焕英》, 就是案 例。

\section{2. 文创产业与第四波经济}

1980 年, 艾文. 托佛勒（Alvin Toffler）发表了 《第三波 (The Third Wave)》。《第三波》把人类的经 济进程, 划分为第一波的「农业革命」, 在此第一波产 业革命, 让人类五千年步入了农业时代, 自此摆脱原 始的狩猎生活。1 840 年, 蒸汽机的发明引爆了工业革 命, 揭开了「技术导向、机器挂帅」的第二波产业革 命时代, 第二波的「工业革命」, 自此进入以「标准化」 而形成的「大量生产」「「大量消费」。克里斯·安德森

（Chris Anderson，2013）着第三波社会则是以「信息 革命」为前导, 从而改变所有人的工作与生活型态, 后工业时代, 集成电路的微芯片技术引领了信息产业 的兴起, 也根本的改变了人类生活的意义; 第三波的 信息革命, 以芯片和计算机为核心, 数据运算和存储 能力的提升创造了对计算机系统与工具需求的庞大 商机。

随着人们对于生活上的质量需求增加, 不断的追 求休闲活动、娱乐及艺文活动, 增加现今人们的文艺 气息，继农业、工业、信息硬件及网络革命后，史上 第四波的文化创意产业革命，随着时代的转变而来临。

随着各国的产业政策趋势发展, 许多国家纷纷转 型至文化创意产业, 英国是全球首个重视发展文化创 意产业的国家，英国首相布莱尔（Tony Blair）最早在 1997 年提出「创意产业」(Creative Industry), 首创筹 设了「创意产业筹备小组」, 针对文化与创意面进行 产业发展政策。英国创意产业定义是「结合创造力、 技术和天赋, 有潜能利用智慧财产来增加财富和就业 的产业」, 范围包括 13 种产业, 从建筑、工艺品、设 计、古董、时尚设计、音乐、表演艺术、视觉艺术、 广告、电影、媒体及计算机游戏出版、软件及电视广 播影视, 均含括在内。文创产业的推动, 英国之后依 序是美国, 日本, 如今两岸三地均极为重视, 如同布 尔优夫森 (Erik Brynjolfsson, 2014)、麦克费 (Andrew McAfee，2014）所说的「第四波经济。」

由于文化资产的特质有其无限性、差异性、共享 性、可变性及丰富性, 配合现在社会发展的趋势, 第 三波经济由高科技主导的现象, 已渐渐转趋为以文化 创意产业为主的第四波经济。

2012 年台湾行政院将文化创意产业被视为「第四 波经济」的推动力量, 文化的创造力不仅是生活方式 显现, 也可以是经济产值的源头, 透过影视产业与文 化工业的结合, 有机会展现第四波力量一文创产业的 价值。

台湾文创产业在影视业过往累积足够能量, 成为 促进经济发展的第四波力量, 如今随着文创产业的创 新、创意, 在传统或科技产业上进行加值化、差异化, 达到产业文创化目标, 提升附加价值, 让影视产业成 为台湾结合文创发展的重要亮点。

经由这样的理念与模式, 逐步推广至各项产业及 区域, 过去台湾投资文创只是将制造业量产概念移植 
到文创产业, 或是以为复制好莱坞经验就能获利; 现 在台湾文化部把重心放在跨域整合，包括形象商圈、 商店街、小区营造、文创园区、观光工厂、伴手礼、 设计旅店、民宿等创新概念, 进行各项周边文创产品 的研发, 都已融合文化与产业的精髓, 而且数量、规 模也愈来愈多元。汪志忠、陈美甜 (2013), 在文化群 聚之关键发展因素分析: 台中创意文化园区的个案分 析〉表示, 此等政策乃旨在把现代的创新, 融合历史 元素, 让文创园区添加一股新风貌, 成为了现代的流 行新趋势, 也带动在地的产业文化及经济发展。

近年來, 文化观光的需求不断成长, 观光与文化 的结合, 许多都是来自于影视产值, 柯金存、蔡进发、 陈碧秀 (2015) 的研究〈自我意象一致性、情感性地 方依附、旅游满意度与未來行为意图关系之研究〉表 明, 像是台湾电影《㾂子英雄》带动高雄观光、《赛德 克. 巴莱》促进原住民文创产业发展, 而全球也相当 重视, 各国皆相继发展文化观光。影视产业带动的不 仅是票房产值，包括观光业等均能受惠。

从影视业出发的文化创意产业是以「创意、加值、 内容」为重点的产业, 必须要有「文化产业化」与「产 业文化化」的思维, 才能达成文化传播的目的性, 也 才能让文化传播更佳具有广度与效度。

\section{3. 台湾电影全球产值}

文创产业在台湾的发展已久, 其中电影产业更是 曾是亚洲之光, 曾经与香港并列风靡华语世界, 然则 自 2000 年后, 台湾电影产业没落, 但是仍不时有许 多好作品, 成为卖座电影, 达成文化传播的效果。

以历来台湾自产电影在台湾卖座排名析论, 《我 的少女时代》在台湾票房是新台币 4.1 亿, 是 2015 年 台片在台湾的卖座冠军, 在历年台片的全台票房排行 榜排名第 5 , 略输给《那些年, 我们一起追的女孩》 的 4.25 亿票房。

从表 1 来看, 由票房 / 成本比, 台片卖座排名第 一的《海角七号》以 4.64 的效益遥遥领先, 其次是 《那些年, 我们一起追的女孩》的 3.63、《我的少女 时代》的 1.86、《赛德克巴莱(上): 太阳旗》的 1.05 。 甚至可以说, 《赛德克巴莱(上): 太阳旗》在扣除高昂 的制作成本后, 票房盈余所剩无几, 远不若前几部的 效益。

表 1 台湾电影历史累积票房

\begin{tabular}{|c|c|c|c|c|c|}
\hline 排名 & 电影 & 片中年代 & 累积票房 & 制作预算 & $\begin{array}{c}\text { 票房/成本 } \\
\text { 比 }\end{array}$ \\
\hline 1 & 海角七号 & $\begin{array}{c}2005 \text { 年左 } \\
\text { 右 }\end{array}$ & $232,326,877$ & 5,000 万元 & 4.64 \\
\hline 2 & $\begin{array}{c}\text { 那些年, 我 } \\
\text { 女起追的 }\end{array}$ & 1994 & $181,604,478$ & 5,000 万元 & 3.63 \\
\hline
\end{tabular}

\begin{tabular}{|c|c|c|c|c|c|}
\hline 3 & $\begin{array}{c}\text { 我的少女时 } \\
\text { 代 }\end{array}$ & 1990 年代 & $158,731,830$ & 8,500 万元 & 1.86 \\
\hline 4 & $\begin{array}{c}\text { 赛德克巴莱 } \\
\text { (上): 太阳 } \\
\text { 旗 }\end{array}$ & 1930 & $\begin{array}{c}\text { 上集约上集 } 3.7 \text { 亿 } \\
\text { 元 }\end{array}$ & $\begin{array}{c}\text { 賽德克巴莱(上)、 } \\
\text { (下)合计 7-7.5 亿元 }\end{array}$ & 1.05 \\
\hline
\end{tabular}

注：※电影票房来源：电影观测站、财团法人国家电影 中心。※作者整理。※单位: 新台币

但是从表 2 来看, 《我的少女时代》是台湾电影 全球票房第一名的电影, 也是韩国史上最高票房的华 语电影, 《那些年》则曾是香港票房史上的冠军, 均可 以看出台湾电影在全球华文市场有其价值, 能够带动 产业发展。

表 2 台湾电影历史全球票房

\begin{tabular}{|c|c|c|c|}
\hline 名次 & 年份 & 片名 & 票房 \\
\hline 1 & 2015 年 & 我的少女时代 & 25 亿 \\
\hline 2 & 2011 年 & 那些年, 我们一起追的女孩 & 12 亿 \\
\hline 3 & 2014 年 & 㾂子英雄 $2:$ 黎明再起 & 10.5 亿 \\
\hline 4 & 2012 年 & 爱 & 8.3 亿 \\
\hline 5 & 2008 年 & 海角七号 & 5.3 亿 \\
\hline 6 & 2012 年 & 㾂子英雄首部曲: 全面开战 & 5.2 亿 \\
\hline
\end{tabular}

注：※电影票房来源：财团法人国家电影中心。※作者 整理。※单位: 新台币

导演魏德圣的《海角七号》在 2008 年带动台片 风潮, 至今仍以 5.3 亿稳坐台湾电影全台卖座榜冠军。 亚军《赛德克 - 巴莱(上): 太阳旗》也是魏德圣执导, 票房 4.3 亿，上下集票房总和 8.1 亿。魏德圣从不同 角度讲发生在台湾这块土地的故事, 不管是日本人还 是原住民, 都让台湾文化更丰富多元, 也是台湾电影 在 2000 年后复兴的关键。

第 3 名的《大尾鲇鳗》则是第一部猪哥亮真正主 演的贺年片, 全家带着阿公阿嬤一起看片, 在 2013 年 创下 4.3 亿佳绩, 中南部的票房比北部更好。猪哥亮 将在 2016 年推出《大尾鲇鳗 $2 》$, 连续 4 年以「猪式 笑料」在春节档扛票房。

历年台湾电影全台卖座排行榜前 3 名都以浓厚 台味与在地观点, 受到台湾观众认同。魏德圣导演的 电影因为政治因素票房在大陆表现不佳; 猪哥亮也尚 未成功进入大陆市场。相对之下，回忆过往青春、笑 中带泪的小清新台片《那些年》与 《少女时代》, 因为 在星马港中等海外市场大有斩获, 总票房大幅超越台 湾市场。

因此《我的少女时代》全球票房第一的意义，足 以做为文本的代表性，证明对于文化产业而言，是能 够在全球传播中获得一席之地，日本翻拍也《我的少 女时代》、《那些年》, 《那些年》电影中的场景像是精 诚中学、八卦山大佛、阿璋肉圆、中华陆桥、彰化渔 市场与永乐街商圈、金瓜石、平溪天灯等知名景点, 之后也成为观光的重要指标, 借着电影有效宣传台湾 彰化的观光景点, 仍是极具有文化传播的产业价值, 所以文创产业不仅能够创造产值, 也有跨文化传播的 意义。

《那些年, 我们一起追的女孩》《《我的少女时代》 
成功地复刻了一系列 90 年代的港台流行文化符号, 如同 2021 年迄今大陆票房冠军《你好，李焕英》一 般, 塑造出记忆中的美好时代。透过青春的循环往复 作用, 引用流行文化元素和少女文化, 而且这 3 部电 影的人设相仿, 少女人设都为追求个性自由, 追求自 我爱情, 对身边的每一个人付出真诚的爱, 并且重现 着过去的美好年代。文创产业在电影中确实找到产业 化的可能性, 并且透过复制进行文化工业化, 产制出 一部又一部的卖座片。

\section{4. 结论}

根据联合国教科文组织下的国际作者和作曲者 协会联合会 (CISAC) 发布的全球文化和创意产业研 究报告, 针对广告、建筑、出版、电影、音乐、表演 艺术、广播电视、视觉艺术等 11 个产业进行调查, 全球文创产业产值达 22,500 亿美元, 创造 2,950 万个 就业机会; 亚太地区文创产业总产值 7,430 亿美元, 占文创产业全球产值 33\%, 从业人员 1,270 万, 占文 创产业全球从业人员的 43\%。足以证明文创产业已经 是全球重要的产业, 虽然在疫情的影响下, 2020、2021 年的电影产业受到重创, 但是整体趋势依然是极受重 视。

以亚洲最重视文创产业的韩国为例, 根据南韩半 官方组织「文化产业振兴院」(KOCCA) 统计, 2017 年南韩文创产业产值高达 110.4 兆韩元（约新台币 3.30 兆元), 甚至与南韩半导体业产值相当, 最大的 诱因, 就是就在于韩国强力推行影视产业, 带动文创 产业相关的整体发展。

阿多诺在《文化工业再思考》中解释了使用文化 工业的动机, 他认为文化工业刻意为大众消费生产, 并在很大程度上决定了消费性质的产品, 或多或少是 按照计划炮制出来的, 并且用心地自上而下整合它的 消费者。也因此文创产业所着眼的文化, 可以说是人 造制品, 而非与传统定义文化的相关, 是透过传播所 塑造的文化意涵。

由于主流与小众影视文化表现形成的商业化产 品, 所获得的大众肯定形成了制度化的认证, 未来文 化知识内涵的商品, 学者廖世璋 (2011) 认为, 在文 创产业会有更高的含金量, 并且足以形成产业化的文 化资本, 进而带动周边文化工业与文化创意产业的发 展。在这样的产业效应下, 电影的发展更是具有未来 性。

当 1980、1990 出生者成为电影消费的主力时, 1990 年代的青春怀旧已然成为两岸三地票房的一大 保障。透过旧场景、旧物品、旧歌曲成为高票房的保 证，怀旧故事的集体记忆也在现代再被唤醒。

对 1990 年代的记忆怀旧, 成为一种历史符号的 表象化, 将消费者的青春浓缩成为上个世纪的文创商 品符号, 封装进入电影传播当中, 更成产业的新思维。

《我的少女时代》是否是 1990 年代社会大多数
人的生活, 还是中产阶级或是特定族群的记忆, 其中 或许仍有疑义, 但是透过电影符码的传播, 却成为现 代人共享拥有的青春集体记忆。这种重塑的集体记忆, 成为千篇一律的文创商品, 忽视了社会阶级差异的面 向, 让消费者透过不断的记忆消费, 重构出共同的记 忆。

记忆的建构是可以包含经验、文字、影像、论述 及文物等, 不断的作选择性地的重整和修改。学者余 做英（2007）在〈集体记忆和香港〉中表明，媒体科 技的急速发达, 加速重整集体记忆的速度, 甚至能够 抹掉某些集体记忆或催生了新的集体记忆。让记忆在 传播之中产生改变, 再创造出新的文化。

随着文创产业的发展, 传播也越受重视, 透过电 影的传播效应, 带动的不仅是票房, 还有城市观光、 文化商品等长期经济效果, 在产业发展上, 仍非常值 得重视。

\section{REFERENCES}

[1] Chen, X. (1996) Cultural Industry. Yangzhi Culture Publishing, Taipei.

[2] Chen, J. (2005) Motor Racing: Regulation, Pleasure, and the Triple Helix of Cultural Industry. Tunghai University, Taichung.

[3] Han, B. (2014) Culture and Cultural Creation. Lianjing publishing, Taipei.

[4] Anderson. C. (2013). The Age of Self-Makers: Initiating the Third Industrial Revolution Made by Everyone. Tianxia Culture publishing, Taipei.

[5] Brynjolfsson, E. (2014) How does smart technology in the second machine age change the work, economy, and future of mankind?. World Culture publishing, Taipei,

[6] Wang, Z., Chen, M. (2013) Analysis of the Key Development Factors of Cultural Clusters: A Case Study of Taichung Creative Cultural Park. Public Affairs Review, Issue 14, Volume 1 : P. 87-106.

[7] Ke, J., Cai J., Chen, B. (2015) Study on the Relationship between Self-Image Consistency, Emotional Local Attachment, Tourism Satisfaction and Future Behavior Intentions. Jiada Sports, Health and Leisure Journal, Issue 14, Volume 1: P. 24-25.

[8] Yu, Y. (2007) Collective Memory and Hong Kong. Cultural Studies@Lingnan, Issue 4:P. 1-3.

[9] Liao, S. (2011) Cultural and Creative Industries. Juliu Book, Kaohsiung.

[10] Sheng, C. (2018) Cultural Industry and the Construction of Collective Memory: Taking "My Girlhood" as an Example. Journal of General Education and Multiculturalism, Issue 7:P. 45-67. 